\title{
POLÍTICA, PRÁCTICA ASOCIATIVA, FORMAS DE COMUNICAR. LA EXPERIENCIA DE UN CASO EN BUENOS AIRES EN EL CONTEXTO DE LA REVOLUCIÓN
}

\author{
Fabián Herrero \\ Consejo Nacional de Investigaciones Científicas y Técnicas, Universidad de Buenos \\ Aires (CONICET Instituto Ravignani, UBA). \\ Universidad Autónoma de Entre Ríos (UADER) \\ herrerofab@yahoo.com.ar
}

El presente estudio centra su atención en una de las cuestiones sustantivas que surgen luego de la Revolución de 1810: cómo comunicar al pueblo y cómo ilustrar a los jóvenes de la élite. Tales cuestiones pueden ser vistas a partir del análisis de muy diversos ámbitos. En este caso, tomamos dos en particular: algunos aspectos de la práctica asociativa (esto es, distintas asociaciones de neto corte filantrópico, destinadas tanto a la ayuda de los más necesitados como a la promoción de materias educativas) y las reflexiones públicas sobre cómo debe intervenir la prensa. Para tratar de comprender estas cuestiones, examinamos la experiencia del fraile Francisco Castañeda. Si bien sus biógrafos han señalado sus iniciativas asociativas, no las ban investigado. Por su parte, sus aportes al debate sobre la prensa no ha sido ni siquiera mencionadas. Este trabajo se ocupa de ambas cuestiones tratando de comprender qué papel asigna Castañeda tanto a esas prácticas asociativas como a la prensa en relación a las formas de comunicar y a cómo instruir a los miembros juveniles de la élite.

Palabras Clave: Política-Buenos Aires, Francisco Castañeda-prensa-asociaciones.

\section{Politics, Associative Practice, Ways to Communicate. The Experience of a Case in Buenos Aires in the Context of the REVOLUTION}

The present study focuses on one of the substantive issues that emerged after the Revolution of 1810: how to communicate with the people and how to enlighten the young people of the elite. Such aspects can be seen from the analysis of very diverse areas, in this case, we do it 
particularly from two: some aspects of the associative practice and the public reflections on how the press should intervene. To try to understand these questions, we examine the experience of Friar Francisco Castañeda. His biographers have pointed out their associative initiatives but have not investigated them. Moreover, his contributions to the debate on the press have not even been mentioned. This work deals with both questions trying to understand what role Castaneda assigns both to these associative practices and to the press, in relation to the ways of communicating and how to instruct the youth members of the elite.

KEYWORDS: Politics, Buenos Aires, Francisco Castañeda, press-associations.

En Buenos Aires, el sistema colonial se derrumba abruptamente en Mayo de 1810. En su lugar, se instaló un sistema de poder centralista que, desde esa ciudad capital y durante casi toda una década, pretendió poner en obra ideales y valores de corte republicano al resto de los territorios del ex Virreinato del Río de la Plata. Institucionalmente, ese centralismo se expresó en distintas figuras, como las Juntas de Gobierno, Triunviratos y Directorios, que fueron modificando sus estilos de gobierno. De 1810 a 1815 sobresale un estilo «autoritario militar», basado en la imposición violenta. Con el derrumbe del Directorio en aquel último año, se produce una crisis de autoridad producto de situaciones diferentes. Mencionamos las principales: las derrotas militares contra los realistas en todas las fronteras; un nuevo poder alternativo de corte confederal impulsado por José Artigas en la Banda Oriental y las provincias limítrofes; el descontento, además, de las ciudades y pueblos por la imposición por la fuerza de su política centralista y, finalmente, por la restauración del monarca español. Entre los años 1816 y 1819, como consecuencia directa de las lecciones de los años previos, un nuevo Directorio impuso un estilo de autoridad diferente, basada ahora en un «consenso conservador» sustentado en la relación con los grupos locales influyentes de los territorios del Interior y un mayor respeto hacia el statu quo. ${ }^{1}$

En ese suelo público permanentemente alterado, se discute, entre otras cuestiones, las formas que debe adquirir esa estructura de autoridad, centralista o confederal, o bien cómo acceder al poder, por elecciones o por la superioridad de la fuerza. Pero también figuran dos ejes temáticos que nos interesa analizar: la difusión de prácticas asociativas y las reflexiones sobre las formas de intervención de la prensa. Ambas constituyen una preocupación de las élites porteñas, quienes tratan de buscar las mejores estrategias tanto para instruir como para informar al pueblo. Ambas líneas temáticas son materia de indagación aquí a partir de un caso particular, el del fraile franciscano Francisco de Paula Castañeda, quien, como veremos, mantuvo una intensa y conocida actividad pública en

1. Sobre este proceso histórico véase especialmente Halperin Donghi, Tulio, Revolución y guerra. Formación de una élite dirigente en la Argentina criolla, México, Siglo XXI, 1972. Una visión crítica sobre esta mirada histórica en Herrero, Fabián, «De la política colonial a la política revolucionaria», en Fradkin, Raúl, Historia de la provincia de Buenos Aires. De la Conquista a la crisis de 1820, Buenos Aires, Unipe-Edhasa, 2012, pp. 325 353. 
los dominios de la política, la prensa, y también en cuestiones vinculadas con la Iglesia. Dividimos esta investigación en dos partes. En la primera, describimos y analizamos sus iniciativas sobre prácticas asociativas. En la segunda, centrada en el ámbito de la prensa, ponemos el foco de atención en una polémica que lo tiene como protagonista en el año 1815. La discusión gira en torno al modo más adecuado para escribir y comunicar al público.

Los historiadores que se han ocupado de examinar la trayectoria vital del fraile, si bien mencionan algunas de las actividades asociativas que fomentó, no las han investigado. Por otro lado, no han registrado el mencionado debate que protagoniza. ${ }^{2}$ En este sentido, el presente trabajo intenta ser un primer aporte sobre estas líneas temáticas dentro de las actividades públicas del fraile. Por lo demás, resulta del todo pertinente señalar que se han publicado en estas últimas décadas algunos trabajos sobre la intervención del franciscano con relación a su tarea de escritor y a su interés por la prensa, pero también sobre sus sermones y algunas de sus polémicas. Varios de ellos, como también las obras de sus biógrafos, nos serán de utilidad para el presente artículo. ${ }^{3}$

Por otro lado, existen estudios sobre otras experiencias históricas que, aunque no podamos indagar exhaustivamente, para no exceder los objetivos previstos para nuestro trabajo, pueden ser un buen mirador para poder comprender mejor el que aquí analizamos. En primer lugar, resulta útil señalar un estudio reciente de Troisi Melian, en el cual ha mostrado cómo la orden franciscana, la que integra Castañeda, vincula la actividad religiosa con la política. A partir de esta perspectiva, describe y analiza el caso de Córdoba, donde frailes redactan periódicos o integran sociedades filantrópicas. Otro caso muy interesante es el de Montevideo en los primeros años de la revolución. Aquí también, política y prensa están ligadas en la intervención de un franciscano. Se trata de Cirilo Alameda, quien redacta la Gazeta de Montevideo con un discurso contrario a la revolución. Si detenemos nuestra mirada en Paraguay, la cuestión de los círculos de opinión y de

2. Hay varios estudios sobre la obra de Castañeda que contienen una muy valiosa información y que conviene mencionar especialmente. Véase Saldias, Adolfo, Vida y escritos del Padre Castañeda, Buenos Aires, A. Moen y hermano, 1907; Furlong, Guillermo, Vida y obra de Fray de Paula Castañeda: un testigo de la naciente patria argentina: 1810-1830, Buenos Aires, editorial Castañeda, 1994; Otero, José Pacífico, El padre Castañeda: su obra ante la posteridad y en la historia, Buenos Aires, Cabaut y Cía, 1907; Capdevilla, Arturo, La Santa Furia del padre Castañeda. Cronicón porteño de frailes y comefrailes donde no queda títere con cabeza, Madrid-Barcelona, Espasa-Calpe, 1933.

3. Véase Auza, Néstor, «Estudio preliminar», en Doña María Retazos. Francisco de Paula Castañeda, Buenos Aires, Taurus, 2001, pp. 3-11. Herrero, Fabián, «La idea de independencia durante los días de la Revolución americana y de la Restauración europea. El difícil sermón patriótico de Francisco Castañeda en la Catedral de Buenos Aires», Revista Iberoamericana. América Latina, España, Portugal, Instituto Ibero-Americano, n. ${ }^{\circ} 45$, Berlín, 2012, pp. 59-79. Herrero, Fabián, «¿Reformar las instituciones de la iglesia? La polémica entre Francisco Castañeda y Feliciano Cavia. Buenos Aires, hacia fines de 1810», Revista Eletrônica do Programa de PósGraduação em Ciências Sociais da UFJF <http://www.editoraufjf.com.br/revista/index.php/csonline/index>, n. ${ }^{\circ} 13,2012$, pp. 48-78. Desde la mirada de la literatura hay trabajos que merecen destacarse: Baltar, Rosalía, «Francisco de Paula Castañeda: amanuense y autor», Cuadernos de Ilustración, n. ${ }^{\circ}$ 20, 2014, pp. 20-41; Roman, Claudia, La prensa de Francisco de Paula Castañeda: sueños de un reverendo lector (1820-1829), Biblioteca Orbis Tertius/10, Universidad Nacional de La Plata, 2014, pp. 10-150. 
la prensa es muy escasa y hay que esperar hasta la segunda mitad del siglo XIX para encontrar, por ejemplo, un periódico con estabilidad y permanencia duradera, más allá de la experiencia previa del Paraguayo independiente. En las llamadas provincias del Interior, entre ellas Jujuy, La Rioja, Catamarca o Tucumán, se ha advertido sobre la escasa presencia de asociaciones y de prensa. El caso tucumano, por ejemplo, muestra que apenas surgen a la luz pública dos periódicos de vida breve a comienzos de 1820 y, en efecto, hasta la década de 1840 no advertimos otras experiencias de este tipo. ${ }^{4}$ Estos pocos casos nos muestran realidades muy dispares y, como se verá, resultan diferentes al de Buenos Aires.

Llegados a este punto, se impone que brevemente mencionemos algunos aspectos de la vida del fraile Castañeda. Nace en Buenos Aires en 1776 y muere en Paraná en 1832, sus restos fueron trasladados a la primera de ellas por la gestión del gobernador porteño Juan Manuel de Rosas. Su origen familiar pertenece a los sectores notables. Su padre, Ventura, tiene algún tipo de parentesco con agentes militares de importancia que se desempeñaron en los períodos de Carlos II y Felipe III. Se ordena sacerdote en la Orden franciscana. En la ciudad de Córdoba estudia filosofía y teología. Antes de 1805, retorna a la ciudad de Buenos Aires, estableciendo su domicilio en el Convento de la Observancia en la Recoleta. Desarrolla una intensa actividad pública: entre otras ocupaciones, pronunció sermones patrióticos de importancia en la catedral de Buenos Aires; editó y redactó más de veinte periódicos, destacando no solo por su imaginación en la forma de expresarse sino por el esfuerzo de escribir varias publicaciones de forma simultánea; y fue uno de los opositores más enérgicos de los federales que invadieron la provincia en 1820 pero también un duro polemista de los miembros del Partido del Orden en el marco de la reforma del clero. Como escritor público, acusado de injuriar al gobierno, atravesó en tres ocasiones la pasarela judicial. Tuvo, además, un activo papel como educador de primeras letras en Buenos Aires, Santa Fe y Paraná. Así pues, su vida atravesó distintos ámbitos, como la Iglesia, la política y la prensa, y, mediante ellos, alcanzó resonancia no solo entre la población en general sino también entre los círculos de la élite.

\section{Imaginación y voluntad: prácticas educativas y culturales}

A partir de la experiencia del fraile Castañeda, investigamos distintos aspectos relacionados con su voluntad de promover actividades ligadas a prácticas en el terreno educativo

4. Troisi Melean, Jorge, Socios incómodos. Los franciscanos de Córdoba en una era de transformaciones (1767-1829), Rosario, Prohistoria, 2016; Lafit, Facundo, «Usos de escritos y conceptos políticos en ambas márgenes del Plata y del Atlántico. La Gazeta de Montevideo, entre Cádiz y Buenos Aires»; Caballero Campos, Herib y Carlos Gómez Florentín, «"En un estilo claro, sencillo y sobre todo, tan útil”. El Semanario De Avisos y Conocimientos Útiles (1853-1868)»; Nanni, Facundo, «Precario como el papel. Los primeros periódicos en el Tucumán decimonónico». Los tres trabajos en Pasino, Alejandra y Fabián Herrero (comp.), Prensa y Política en Iberoamérica, Editorial de la FFyL, UBA, 2018 (en prensa). Véase además, Nanni, Facundo, «El arte de la difamación: las disputas al interior de la élite en el Tucumán de la década de 1820», Revista Navegamérica, n. ${ }^{\circ}$ 11, Murcia, Universidad de Murcia, 2013, pp. 15-37. 
y cultural. En un primer momento, centramos nuestra atención en las distintas iniciativas de prácticas asociativas; luego examinamos de modo particular la promoción de la Academia de dibujo y, finalmente, analizamos algunos indicios que puedan darnos una imagen sobre el impacto que tuvieron.

\section{El esfuerzo por promover prácticas asociativas}

A lo largo de su vida pública, Castañeda impulsa distintas asociaciones de neto corte filantrópico, destinadas tanto a la ayuda de los más necesitados como a la promoción de materias educativas. ${ }^{5}$ Antes de explorar su punto de vista, resulta del todo pertinente conocer a grandes rasgos qué sucede con relación a estas prácticas asociativas en Buenos Aires. Esos datos, claro está, pueden ayudarnos a entender si el fraile inserta su iniciativa en una trama ya instalada o bien si se trata de la obra de un verdadero innovador en esta materia.

La práctica asociativa no es una especificidad de la ciudad independiente. ${ }^{6}$ Los pequeños espacios urbanos coloniales experimentan un desarrollo importante de las formas de organización religiosa, como las cofradías y las Terceras órdenes. Este modelo asociativo tiene un origen español y, al parecer, tiene un desarrollo relativamente rápido en el continente americano. En el caso de Buenos Aires, a partir de una investigación pionera de José Torre Revello, ${ }^{7}$ es posible saber que para el año 1609, en una ciudad que solo cuenta con aproximadamente quinientos cincuenta habitantes, ya se han instalado dos cofradías. Catorce años después, trece cofradías están al servicio de la salvación de las almas de casi dos mil porteños. El tema, claro está, requiere de nuevos estudios para conocer con más detalle esa trayectoria. Sin embargo, gracias a un inteligente estudio de Pilar González Bernaldo podemos establecer alguna conjetura. La historiadora considera, a partir de algunas referencias indirectas, que esta forma relacional aún mantiene vitalidad a principios del siglo XIX. Según parece, posteriormente, este tipo de hábitos relacionales declinan, y es posible que esa decadencia se produzca en beneficio de las nuevas prácticas asociativas laicas. Un serio indicio que puede respaldar esta postura es el hecho de que en territorio americano, prácticamente en todas las ciudades donde las élites criollas participan en la insurrección, se implantan sociedades políticas, más o

5. Las sociedades filantrópicas tienen su origen en un fin de carácter altruista. Su intención puede orientarse a sujetos y actividades diferentes vinculadas por ejemplo a la protección o la educación de los jóvenes o los desvalidos, pero también literarias o de otras disciplinas. En general, son solventados por alguna autoridad y sus integrantes suelen ser de los sectores de la élite de distinto nivel.

6. Particularmente González Bernaldo, Pilar, Civilidad y política en los orígenes de la nación Argentina. Las sociabilidades en Buenos Aires, 1820-1852, Buenos Aires, Fondo de Cultura Económica, 2008, pp. 96-97. Véase además, Molina, Eugenia, El poder de la opinión pública. Trayectos y avatares de una cultura política en el Río de la Plata, 1800-1852, Santa Fe, ed. UNL, 2008, pp. 129-278.

7. Torre Revello, José, «Fiestas y costumbres», en Academia Nacional de la Historia, Historia de la Nación Argentina. De los orígenes hasta la organización definitiva en 1862, Buenos Aires, Academia Nacional de la Historia, 1951, pp. 40-62. 
menos formalizadas, denominadas clubes, sociedades patrióticas, logias o simplemente tertulias. $^{8}$

A los ojos de González Bernaldo, en Buenos Aires, entre este primer esbozo de asociación libre y el auge del movimiento asociativo durante el gobierno de Rivadavia (18211827), hay que señalar por lo menos dos etapas intermedias. ${ }^{9}$ La primera se sitúa entre los años 1806 y 1807: es el momento en que las tropas inglesas ocupan sucesivamente la ciudad y aparecen en Montevideo las primeras logias militares. Según varios testimonios de la época, el interés por esta novedad asociativa no tardó en hacerse sentir, sobre todo entre el público más ilustrado del espacio urbano. La segunda etapa es la que transcurre desde el momento de la insurrección de Buenos Aires en 1810 hasta la declaración de la independencia en 1816. Durante esos seis años nacieron varias asociaciones de tipo sociocultural. Su creación se relaciona, sin duda, con la nueva libertad que acompaña al movimiento insurreccional, pero también con la nueva coyuntura política. Todo parece indicar que las iniciativas no solo provienen de la sociedad, sino también del poder revolucionario que advierte en la creación de este nuevo tipo de organización un medio para consolidar la revolución entre las élites locales que simpatizan con las nuevas ideas. ${ }^{10}$ Es justamente con el nuevo orden, instaurado durante el gobierno dominado por la impronta de Rivadavia, cuando se produce un desarrollo importante del movimiento asociativo. Se trata de organizaciones que presentan objetivos y contenidos diversos, pero que tienen en común el hecho de fundarse en la adhesión voluntaria de los participantes.

Teniendo presentes los datos señalados hasta aquí, podría decirse que Castañeda promociona la instalación de sociedades filantrópicas en un momento previo al auge registrado en el período rivadaviano, pero en una etapa en donde esa práctica ya tiene una larga trayectoria previa. Esto es, tanto su discurso como su tarea de gestión en esta puntual materia pública no se instalan en un terreno yermo sino en un escenario en construcción.

Pues bien, ¿cuáles son sus iniciativas? Uno de sus proyectos es la denominada «sociedad de los inválidos», la cual es promovida en su arenga de la Academia de dibujo. Su fin es la unión de «todos los inútiles del pueblo», refiriéndose a los que no empuñan las armas, los ancianos y a los hombres de la iglesia. Esta «sociedad de inválidos», a su juicio, tendría la «alta misión» de salvar a la patria «cuidando a la generación venidera». ${ }^{11}$

Una segunda iniciativa remite a una sociedad filantrópica-literaria, que es presentada en el Cabildo de Buenos Aires. Su origen, a los ojos del redactor del periódico Los amigos de la patria y de la juventud, Felipe Senillosa, solo se debe a los buenos propósitos tendientes a propiciar la educación que anima a su autor. Para decirlo con sus palabras, «el indecible zelo con que el P. Castañeda se desvela a favor de la ilustración». La pregunta que los habitantes de Buenos Aires deben hacerse, razona el mismo redactor, es la si-

8. González Bernaldo, Civilidad..., cit., pp. 100 y 101.

9. Ibidem.

10. Ibidem; Ibarguren, Carlos, Las sociedades literarias y la Revolución Argentina (1800-1825), Buenos Aires, Espasa Calpe, 1937.

11. Castañeda, Francisco, «Arenga de la Academia de dibujo», en Segura, Juan, El padre Castañeda y su programa cultural en Paraná, Paraná, Editorial Nueva Impresora, 1948, p. 11. 
guiente: «Es o no útil establecer una sociedad filantrópica-literaria?». ${ }^{12}$ La simple descripción de las metas que esta empresa persigue debería en su opinión convencer a cualquiera de sus beneficios. En efecto, se trata de «un conjunto o reunión de personas hábiles», quienes tendrán como «ocupación principal» impulsar y «promover la industria, hacer florecer la agricultura y cultivar las artes». En la mirada optimista del articulista, una iniciativa de este tipo «no puede menos de traer consigo un buen resultado». En esta línea, Senillosa señala que en esta hora de la Revolución es necesario apoyar y respaldar el proyecto de Castañeda ya que «conviene sobre manera que las ideas circulen», sobre todo porque se trata de «una sociedad formada de los hombres amantes de la ilustración», cuyo fin es el «de propagar las luces y ser útiles al país». ${ }^{13}$

Ahora bien, ¿cómo justifica las iniciativas de esta empresa asociativa? La cuestión que, en su opinión, resulta del todo pertinente plantear es si las circunstancias que rodean a un proceso revolucionario convulsionado por un escenario guerrero pueden permitir la realización de este tipo de tareas. Negarse a concretar este tipo de iniciativas constituye a sus ojos un serio error, ya que en «el estado de la guerra en que una nación se halla lejos de hacer perjudicial a esta clase de establecimiento les es, antes bien, favorable». ${ }^{14}$ ¿Por qué? Porque «durante las guerras civiles o de revolución» es, sobre todo, cuando los «ánimos, en mayor exaltación hacen a cada individuo capaz de mayores empresas». ${ }^{15}$ Según su interpretación, los ejemplos históricos abundan. En España, Felipe $\mathrm{V}$, aprovechándose del «juego que la Guerra de Sucesión había encendido», pudo establecer «en Madrid una biblioteca pública, la academia española, la de historia y la de los tres nobles artes». ${ }^{16}$ Desde otro terreno político se pueden extraer conclusiones similares. Es el caso de la Revolución de Francia, «esa catástrofe espantosa», se lamenta el franciscano, «a la cual no puedo volver la vista sin horrorizarme». Allí también, luego de los «baños de sangre, se adelantó en todos los ámbitos del conocimiento». ${ }^{17}$ Este ejemplo, no por casualidad, recorre los periódicos que posteriormente editará Castañeda. A comienzos de 1820, el fraile emplea un tono elogioso para comentar la creación de la universidad «en medio de las bayonetas». En este sentido, sostiene que Buenos Aires sigue el ejemplo de Estados Unidos, que mientras peleaban frente al opresor inglés, creaba «colegios y universidad en los distintos estados». ${ }^{18}$ Lo que propone Castañeda aquí es

12. «Reflexiones sobre la sociedad filantrópica literaria», Los Amigos de la Patria y de la Juventud, Buenos Aires, 15 de noviembre de 1815. Continúa en la misma línea en «De la sociedad filantrópica», Los Amigos de la Patria y de la Juventud, Buenos Aires, 15 de enero de 1816. Esta publicación periódica es editada en Buenos Aires. Durante 1815, su redactor es Felipe Senillosa, un español que huye de su país un poco antes de la aparición del periódico. Su tema principal fue la promoción de la educación pública, por este motivo, se presentan iniciativas de este tipo y reflexiones sobre su utilidad.

13. «Reflexiones sobre la sociedad filantrópica literaria...», cit.

14. Ibidem.

15. Ibidem.

16. Ibidem.

17. Ibidem

18. «Universidad Argentina», Eu Nao Me Meto con Ninguem, Buenos Aires, 14 de agosto de 1821. Este periódico se edita en Buenos Aires, durante el año 1821 y es redactado por el fraile Castañeda. 
pensar en aquellos sujetos que no van a la guerra, los viejos y los jóvenes de la élite, porque serán los miembros de las futuras cúpulas dirigentes. Por eso en su intervención menciona que no hay que pensar solo en las formas estratégicas de hacer la guerra, sino que hay que pensar la guerra en toda su dimensión. ${ }^{19}$

En síntesis, Castañeda trata de pensar la coyuntura revolucionaria. En su opinión, las crisis políticas y las contiendas bélicas, más allá de su importancia en sí mismas, no constituyen suficientes motivos para justificar la ausencia de preocupación de otros temas, como la educación. En este punto, trata de incidir en la agenda pública de la élite política.

Un último punto sobresaliente remite a la circulación dentro del discurso que promueve el proyecto de Castañeda del vocablo «igualdad», el cual aparece por ejemplo en las páginas de El Censor. Ahora bien, ¿se producirá en la sociedad filantrópica propuesta una reunión de iguales? Sus promotores, como se ha visto ya, pensaban que ella conformaría un recurso pedagógico clave para la élite porteña, no solo para generar un debate racional sino también como vía de inculcación de valores nuevos. No obstante, algunas zonas dentro del esquema argumental del órgano de prensa capitular señalan claramente la palabra igualdad que es necesario examinar y explicar. ¿Qué dice? Dice justamente que «allí veremos» que en el espacio que ofrece una «sociedad justa y racional no halla lugar la feroz bestialidad del despotismo, ni la esclavitud inhumana del vasallaje», hecho que «destruye la igualdad que da la naturaleza y corrobora la sabia legislación». ${ }^{20} \mathrm{Y}$ en esta misma línea, seguidamente, menciona de modo general a los sectores menos favorecidos: «allí aprenderemos que toda autoridad ha sido establecida solo para el bien de los pueblos» y también para «proteger al pobre contra las tropelías y usurpaciones de los poderosos, defendiendo la inocencia contra la calumnia». ${ }^{21}$

Ese principio igualitario, como señala Eugenia Molina, tiene dos contradicciones. Por un lado, es claro, como se ha advertido ya, que no se convoca a cualquier individuo. Basta evocar en este preciso sentido una de las columnas de La Gazeta, en donde claramente se señala que aquellos son particularmente los ciudadanos «respetables por sus oficios, por sus luces, por su estado». ${ }^{22}$ Conviene tener presente, además, que solo se

19. Herrero, Fabián, «La guerra revolucionaria. Algunas propuestas en el dominio público de Buenos Aires», inédito, 2018.

20. El Censor, Buenos Aires, 6 de junio de 1816. Este periódico se edita en Buenos Aires entre los años 1815 y 1819 . Nace como expresión del Cabildo porteño a partir de una iniciativa del Estatuto Provisorio de 1815 , con la intención de que la autoridad posea su propio órgano de prensa diferente a la del Gobierno. Su redactor es el cubano Antonio José Valdés, quien durante el año 1815 redacta también La prensa Argentina. La particularidad de estas publicaciones es que confrontaban públicamente como si fueran escritas por periodistas distintos.

21. Ibidem

22. «Sociedad Filantrópica de Buenos Aires», La Gazeta, Buenos Aires, suplemento, 30 de diciembre de 1815. Este periódico expresa las posiciones del gobierno «nacional» y es la que más permanece en el tiempo, 1810-1821. Durante el año 1815 es redactado por Fray Camilo Henríquez, que nace en Valdivia (Chile). Es sacerdote y escritor público. En su paso anterior por Chile ejerce el periodismo pero también se desempeña en cargos públicos. 
consideraron socios natos a los miembros de las corporaciones, quienes tienen el privilegio de no pagar el canon exigido al resto de los socios. De hecho, la escuela central recibirá sólo a los hijos de éstos o sus parientes cercanos, remarcando su función como espacio para formar y reproducir en la élite la nueva civilidad, perpetuando su rol como referente social. ${ }^{23}$

En suma, la incursión en la empresa asociativa del franciscano no es obra exclusiva de él, su iniciativa se inserta en un espacio, Buenos Aires, en donde la huella de esa práctica tiene una larga historia. Se trataría de un ámbito en que los hombres solo se relacionan con las ideas. Su objetivo es una didáctica que pretende cambiar los llamados «abusos» y «vicios» que anidan socialmente y en la promoción de ideas ligadas al trabajo. No hay allí un principio igualitario que incluya a los sectores menos favorecidos, sino que los sujetos que la integran forman parte del círculo de la élite local. Se trata, finalmente, de una iniciativa amparada por la esfera estatal. En esta empresa, como en otras ligadas a la difusión de la ilustración, tiene una excesiva confianza, como veremos cuando analicemos su impacto.

En el año 1819, en el marco de la polémica que mantiene con Feliciano Cavia, señala nuevamente la urgencia de instalar prácticas de este tipo:

Damos a Ud. y al público la noticia de que en la Recoleta se está trabajando una disertación en la que se demuestra la necesidad de las sociedades Teofilantrópicas en Sud América, y que sin tales sociedades, costará muchos milagros conseguir lo que con ellas no será más que en efecto necesario de causa necesaria. ${ }^{24}$

Como se ve, es constante su voluntad de gestar empresas sociales ligadas a la educación y a la formación de la élite, pero también lo son sus dificultades serias de funcionamiento por la debilidad de sus apoyos, tanto de la esfera estatal como de la que puede nacer del seno de la sociedad. El tipo de sociedades que piensa no son igualitarias sino de élite, y las ideas que promueve son las de un letrado católico del antiguo régimen: fomenta la educación y la cultura siempre ligada a la religión.

Veamos de modo particular cómo promueve la Academia de dibujo.

\section{La Academia de Dibujo}

Desde un comienzo, tramita esta iniciativa en el ámbito capitular. A fines de mayo de 1815, se puede leer en un acta de sesión del Cabildo de Buenos Aires que

23. Molina, Eugenia, El poder..., cit., pp. 164 y 165.

24. Amonestaciones al Americano, Primera Amonestación al Americano (1819) Biblioteca Nacional. Sala del Tesoro. Véase, Herrero, Fabián, «¿Reformar las instituciones...», cit. Resulta oportuno aclarar que el mencionado Feliciano Cavia es el redactor de El Americano, quien durante aquel año mantiene una polémica con el padre Castañeda sobre cuestiones vinculadas a reformas en las Órdenes de la iglesia. 
se leyó un oficio del Padre Guardián de la Recoleta Fray Francisco Castañeda fecha del día de ayer, en que exponiendo tener establecidas dos pequeñas Academias de Dibujo en aquel convento como tan útiles a la juventud, y que por la distancia carece de Niños de la Ciudad, solicita se interese este Ayuntamiento con el Tribunal de Consulado para que le franquee una de sus Salas a tan loable fin. ${ }^{25}$

Su propuesta, en efecto, no es una promesa de futuro. Se trata de ampliar y continuar una tarea que ya desarrolla en el ámbito de la Iglesia. Hay dos emprendimientos en marcha, lo cual obviamente le permite tener más chance a la hora de obtener el auxilio de la institución municipal, justamente porque hay un trabajo previo que lo avala y que puede mostrar.

Los cabildantes, por su lado, comisionan al Sor Regidor D. Manuel de Zamudio para que solicite de SS. Prior y Cónsules se franquee «una Sala o pieza capaz del Consulado nombrándole también por especial Diputado». Al mismo tiempo, se le encarga que le dé las gracias correspondientes al sacerdote franciscano «a nombre del Cabildo por su loable celo a favor de la instrucción de la juventud». ${ }^{26}$

Finalmente, el trámite se resuelve felizmente. Por un «aviso oficial», el fraile informa al Cabildo que tiene dispuesta la apertura de la Escuela de dibujo para el día 10 de agosto. Le solicita, como es habitual en este tipo de actos, que «disponga se haga con la solemnidad y lucimiento posible, convidando al efecto individuos de otros Tribunales y Corporaciones, y ordenando la concurrencia de los Niños de las Escuelas públicas al Consulado, donde debe celebrarse el acto». ${ }^{27}$ Se resuelve aceptar este pedido encargando para su cumplimiento al Señor Regidor Diputado D. Manuel Zamudio, y

dando las gracias al dicho reverendo padre por la actividad, desinterés, y selo con que propende a tan útil Establecimiento, y asegurándole que éste Ayuntamiento toma desde luego una parte activa e interesante en su protección, todo lo que se le comunique por medio del correspondiente oficio, dándosele además Testimonio de este Capítulo de Acuerdo, para que en todo tiempo pueda exigir de esta Corporación aquella misma protección, que por él dispensa y declara. $^{28}$

La sede capitular ofrece varias cosas, entre ellas, la preparación de una ceremonia con características oficiales, esto es, con asistencia de las autoridades. Al mismo tiempo, se presenta como una especie de protector de la nueva empresa cultural. ¿Qué significa en

25. Archivo General de la Nación, Acuerdos del Extinguido Cabildo de Buenos Aires, serie IV, t. V, Buenos Aires, 1927. Sesión 31 de mayo de 1815, p. 506 (en adelante Acuerdos). Sobre las tensiones en materia educativa entre el Cabildo y el gobierno central luego de 1815, véase, Fracchia, Diego, «Poder político y reformas educativas en la Buenos Aires revolucionaria: debates y representaciones en la prensa, 1810-1820», en Peire, Jaime, Mariano Di Pasquale y Arrigo Amadori, Ideologías, prácticas y discursos. La construcción cultural del mundo social, siglos XVII-XIX, Buenos Aires, EUNTREF, 2013, pp. 293-322.

26. Acuerdos..., cit., p. 506.

27. Acuerdos..., cit., pp. 543 y 544.

28. Acuerdos..., cit., p. 544. 
términos concretos esa protección? De esto no se dice una palabra. Se trata de un respaldo que se da por hecho y que se supone se sabe a qué se están refiriendo. Como se verá, este supuesto creará dificultades que no se observan en este comienzo festivo.

¿Qué puede decirse acerca de su funcionamiento? Un nuevo oficio del padre franciscano ofrece algunos indicios al destacar algunos resultados y señalar un nuevo pedido. Con un tono de inocultable satisfacción, sostiene que «hace presente la mucha gente que concurre a la Escuela de Dibujo», hecho que genera nuevas necesidades y hace visible la ausencia de medidas acordes al flamante emprendimiento. Así, en su relato, afirma que es del todo pertinente «aumentar las salas, y los maestros», advirtiendo que son elementos que el Cabildo «no previó, cuando ofreció su Establecimiento por su cuenta». ${ }^{29}$

No se le escapa que esta novedad constituye una dificultad. Sabe, por cierto, que «la falta de fondos Municipales» no permite pensar ninguna solución cercana. En ese dinero que falta, y que supone previsto como sostén de la Academia, funda «sus esperanzas para auxilio de pago de maestros, y otros gastos». ${ }^{30} \mathrm{El}$ tema, por consiguiente, no es menor y muestra los límites de la protección que se supone la institución municipal prometía dar de forma «activa». Concretamente, apoya la experiencia pero no cubre todos los gastos, solo atiende algunos aspectos: el lugar, los honores y el respaldo al proyecto, pero no le brinda un presupuesto.

Por este motivo, Castañeda propone una alternativa para solventar los gastos. Plantea concretamente lo que denomina «dos arbitrios». El primero es que se

le permita formar con sujetos escogidos una Sociedad filantrópica de Amantes de la educación, cuyo único empleo sea, propagar la ilustración publica a costa de los mayores sacrificios, corriendo por cuenta del Ayuntamiento el conseguir la aprobación del Superior Gobierno, y por la del proponente todo lo demás.

Le recuerda, en segundo término, que «estando los fondos del finado Dor. Roxas destinados para la dotación de dos Escuelas, se apliquen para sostener las dos Academias de dibujo, que hasta ahora están sin dote». ${ }^{31}$ Que el plan que se presenta no es descabellado lo prueba su rápida aprobación, producida, concretamente, solo durante una sesión posterior. No obstante, como se verá, la cuestión de los recursos no terminará aquí: volveremos sobre este tema para mostrar que la respuesta ofrecida no fue suficiente. Lo que se advierte en esta propuesta es que la iniciativa queda a la sola voluntad del fraile y no de la institución estatal local. Su accionar es el de alguien que debe gestionar permanentemente para poder sostener su proyecto. Bien puede resumirse en la fórmula, voluntad y gestión.

¿Qué más puede mencionarse sobre la Academia? Resulta oportuno señalar que su emprendimiento no es una novedad en Buenos Aires. La primera escuela de dibujo es

29. Acuerdos..., cit., p. 509.

30. Ibidem.

31. Ibidem. 
creada por inspiración de Belgrano, Secretario del Consulado, en 1799 y es clausurada poco tiempo más tarde. ¿Hace mención de este hecho Castañeda o pretende distanciarse de aquella experiencia? El franciscano la recoge de algún modo y tiene como objetivo su continuación. Hay indicios concretos que señalarían que esa intención está de alguna manera presente. No es casual que abra su primera clase en el mismo lugar que lo hizo aquél, precisamente en el Consulado. Tampoco puede resultar un gesto inocente que conserve un retrato de él ilustrado por uno de los estudiantes de la Academia: «tengo en mi poder, confiesa el fraile, un retrato iluminado del general Belgrano, dibujado por un joven de mi antigua Academia»y, concluye, «desde ahora lo cedo para que este General, fundador de escuelas, presida el nuevo establecimiento».32 De esta manera, la experiencia de Castañeda no pretende instalarse como un hecho original sino que tiene una historia en la ciudad en la cual pretende anclar su legitimidad.

En suma, la empresa parte de una experiencia iniciada en el ámbito de la institución religiosa y logra con éxito convertirse en una actividad de la institución municipal. Tiene su respaldo, su apoyo económico (por lo menos en parte de lo solicitado) y los honores correspondientes. Esta experiencia se inscribe como una continuación del proyecto de Belgrano, de modo que no parte desde cero. De esta manera su fuente de legitimidad no solo alude a aquella empresa anterior, sino que remite también al apoyo de un ámbito estatal.

\section{¿Qué impacto tuvo?}

La cuestión del impacto puede dividirse en dos partes. La primera consiste en determinar algunos indicios sobre sus resultados, esto es, si prosperaron en el tiempo y si tuvieron apoyo. La segunda alude a saber si sus iniciativas tuvieron una valoración positiva por parte de las instituciones y la prensa.

Que su tarea logra cierta repercusión en algunos ambientes lo prueban algunas descripciones de su perfil escritas por diferentes actores. Durante esos años el fraile es presentado como alguien que dedica su vida a la filantropía, es decir, a servir desinteresadamente a los demás. Como ya advertimos, es lo que señala justamente el Cabildo porteño pero también puede advertirse en la prensa. En una nota, el redactor de La Prensa Argentina lo define como un promotor de la educación y de la beneficencia: «No podemos menos de celebrar el empeño laudable del R.P. Castañeda en cuanto dice a la educación y beneficencia del país». En esta misma línea, continúa: «este benemérito religioso es bastante acreedor a que el público y los magistrados segunden y protejan sus conatos cuando vemos que tienden exclusivamente al beneficio común». Posteriormente, concluye: «su autor no reporta otra utilidad, que la alegría que percibe una alma candorosa que vive para los otros». ${ }^{33}$ Las tareas filantrópicas que se le reconocen son múltiples. Se

32. Castañeda, Francisco, «Arenga...», cit., p. 9.

33. «Nota», La Prensa Argentina, Buenos Aires, 20 de febrero de 1816. 
destaca que el franciscano «estimula a la sociedad filantrópica, como promotora de tantos bienes», «anhela por ver radicada la Academia de dibujo, ofreciendo para su fomento cuantos intereses están en su poder y arbitrio», y también «predica mensualmente en las cárceles, da ejercicios a los encarcelados, y no perdona sacrificios que pueda traer algún bien a sus semejantes».34 Pero esto no es todo. Alrededor del año 1817 , un agente secreto del Rey, envía al monarca un informe sobre los sacerdotes patriotas de Buenos Aires. Su perfil es breve y contundente: «Castañeda, Francisco: fraile franciscano muy estimado en Buenos Aires por su carácter benéfico y sus servicios a la educación pública».35

Ahora bien, con relación al impacto real de las iniciativas asociativas la cuestión es muy diferente. Para empezar, no es fácil precisarlo. Sin embargo, varios indicios pueden mostrarnos que, si hubo un impacto, éste fue relativo o escaso. Castañeda tiene una excesiva confianza en la sociedad que supone va a apoyar su iniciativa y cree en el poder transformador de la educación. No obstante, todo ello resulta exagerado. Los jóvenes no parecen cambiar. Ni están en el camino que él cree que deben recorrer. En los años siguientes, su crítica negativa a este sector es ciertamente importante. En el crítico año de 1820 los cuestiona abiertamente porque a sus ojos se dejan engañar por los federales: los califica de «bobines» por sus acciones ingenuas o los describe con expresiones irónicas como «precioso joven» $\mathrm{o}$ «hijito», señalando su falta de compromiso en la vida, su escasa madurez para hacerse cargo de las cuestiones públicas. ${ }^{36}$

Las sociedades filantrópicas tampoco alcanzan la meta que aspira. No logran anclarse en la realidad porteña. Como advertimos, funda varias en esta década. Tienen, en verdad, una vida efímera. Todas estas iniciativas, impulsadas por el fraile y por varias publicaciones periódicas, caen ciertamente como un torrente sobre una sociedad que mira con indiferencia. Esa indiferencia, por cierto, se ha vuelto circular, y, por lo tanto, infinita. Dos ejemplos pueden ilustrarlo con entera claridad.

La sociedad filantrópica literaria que promueve el padre Castañeda trabaja acompañada por el Cabildo de Buenos Aires, quien de manera particular se ocupa de la selección y convocatoria de trescientos vecinos que debían representar los diversos sectores de la élite local. ${ }^{37}$ Las cosas, sin embargo, no funcionan de acuerdo a las metas previstas. Si bien es posible señalar algunos actos concretos, como la designación de autoridades y el funcionamiento de una comisión encargada de elaborar una normativa, las actividades no presentan en general ni la intensidad ni el vigor prometido. No es casual que en el periódico del Cabildo se apele directamente al Director del Estado para que inicie alguna acción que pueda respaldar la escasa resonancia que la sociedad filantrópica tiene en su

34. Ibidem.

35. Citado en Segura, Juan, El padre Castañeda..., cit., p. 9.

36. Véase «Prospecto de un nuevo periódico», El Desengañador gauchi político, Buenos Aires, sin fecha. «Prosigue la tercera amonestación al joven Perulero, y a su continuador Flor y Nata», El Despertador Teofilantrópico, Buenos Aires, 16 de setiembre de 1820. Los periódicos señalados se editan en Buenos Aires y son redactados por el fraile Castañeda.

37. «Avisos», en La Gazeta, Buenos Aires, 9 de diciembre de 1815. 
entorno. ${ }^{38}$ Evidentemente, hay tensiones y dificultades en la relación entre el dominio institucional y el dominio social. En ese contexto problemático, se sostiene con razón que una vez más «se apelaba a la esfera estatal para consolidar iniciativas particulares». ${ }^{39} \mathrm{En}$ este caso, se advierten varios problemas: instituciones débiles, una sociedad que poco participaba en este tipo de emprendimientos y una voluntad del franciscano que no es representativa de la participación social.

El segundo ejemplo alude a la escasa trascendencia que tuvo la venta de la Arenga de la Academia de dibujo, que estaba destinada justamente a solventar parte de esa tarea. En La Prensa Argentina se publican algunos oficios y remitidos que nos ayudan a analizar qué recepción tiene la arenga. Se publica, por ejemplo, el oficio que el sacerdote franciscano le envía al prior del Consulado de Buenos Aries. En este papel señala que le remite exactamente «quinientos ejemplares» de la arenga pronunciada para la apertura de la academia de dibujo. «Estimare a V.S no le ponga precio», sostiene nuestro escritor, «pues los buenos patriotas me harán el honor de pagarla bien, cuando sepan que todo el producto está destinado para fondos de tan útil establecimiento». ${ }^{40}$ Su confianza en que su pedido será bien recibido no admite discusión. En este preciso sentido, confiesa con esperanza y alegría que «N.M.R.P. provincial Fr. Pedro Nolasco Iturri después de aprobar y bendecir mis empeños patrióticos y arbitrios menesterosos en obsequio de la educación pública, ha tenido la bondad de exhibir diez pesos por un ejemplar a nombre de la provincia». Pero ese no es el único ejemplo a seguir, ya que del mismo modo

esta santa y venerable comunidad de la recolección, como tan interesada en los progresos de la academia, ofrece otros diez pesos por un solo ejemplar, que después de leído lo devolverá graciosamente, para que sea revendido: añadiendo que si no fueran tan apuradas las circunstancias, en que se halla por la escasez de los tiempos, ofrecería el doble más. ${ }^{41}$

Como se ve, más allá de su tono confiado, los fondos recaudados no son muchos. Apenas puede nombrar algún caso. Esas esperanzas no tienen ninguna respuesta positiva en los días siguientes. Una última noticia al respecto puede ilustrarnos que su confianza es enteramente excesiva. En un nuevo oficio enviado a otros hombres de la iglesia, nuestro escritor también aprovecha para mandárselos, ya que «sería hacerles un agravio el no remitirles algunos ejemplares de la arenga impresa, que todos los tribunales de la patria han recibido con el mayor aprecio». ${ }^{42}$ En este sentido, da por descontado que contribuirán con la noble causa que lleva adelante como lo han hecho otros religiosos. ${ }^{43}$

38. «Instrucción Pública», en El Censor, Buenos Aires, 5 de setiembre de 1816.

39. Molina, Eugenia, El poder de la opinión..., cit., p. 164.

40. «Oficio del R. P. Castañeda al prior del Consulado de Buenos Aries», La Prensa Argentina, Buenos Aires, 20 de febrero de 1816.

41. Ibidem.

42. «Oficios comunicados», La Prensa Argentina, Buenos Aires, 19 de marzo de 1816.

43. «Espero que VV... o por medio de amigos espirituales o apurando el corto peculio que es compatible con la pobreza de nuestro estado, se esforzarán a contribuir, como lo ha hecho nuestro M.R.P. Prov. F. Pedro Nolasco Yturri, y los R.R.P.P. de esta comunidad, todo lo que se ha transmitido al público por medio de la 
¿Cuál es la repuesta de esos hombres de la iglesia? En este caso también, a decir verdad, nada sucede como lo espera.

Visto el oficio del Francisco Castañeda, dijeron los R.R. Jorge Canio y el custodio F. Lorenzo Santos que contribuirán con buenos deseos y oraciones, y el R.P. F Pedro Montero, que ni tiene ni puede, o que hará lo mismo que los padres definidores el R.P. P.D.F Francisco Alonso contribuye con 25 pesos y con los mismos contribuirá el R.P. D.F. Santiago Martínez si le pagan lo que le deben... F. Francisco Martínez Def. y Sec. Del Defin. ${ }^{44}$

El hecho señala, con entera claridad, la escasa contribución que hacen aquellos de los que espera una respuesta material y no solo oraciones o buenos augurios. A esta conclusión llega también el redactor de La Prensa Argentina cuando señala, con ironía algo gruesa, que «no podemos de alabar la pobreza ejemplar de los R.R.P.P. F. Jorge Caneo, F Lorenzo Santos y F. Pedro Montero y quedamos persuadidos que a virtud de sus oraciones se fomentaría y prosperaría la Academia de dibujo». ${ }^{45}$

Paralelamente a su voluntad de impulsar iniciativas de corte filantrópico se puede advertir su preocupación por reflexionar y, sobre todo, debatir, sobre cómo hay que informar y comunicar al pueblo. Una y otra actividad están unidas a la idea de impulsar un tipo específico de ilustración.

\section{El papel de la prensa y la «carta tediosa» del padre Castañeda}

Una carta escrita por el franciscano mereció un debate en la prensa porteña. Puntualmente, se discute cuál es la forma y el lenguaje a emplear cuando se interviene en el espacio público. Sobre la carta de Castañeda se pueden encontrar artículos referidos a ella donde le dan, por cierto, un lugar importante en sus páginas. Ahora bien, ninguno de ellos, ni siquiera Castañeda, hace ninguna cita puntual de la carta en cuestión, por lo cual se mantiene esta interesante polémica sobre las formas de comunicar al pueblo. Antes de examinar este episodio, resulta útil detenernos un instante sobre la violencia en el lenguaje en ese dominio, hecho que, como se verá, aparece en la polémica.

\section{Violencia en la comunicación. Algunos indicios}

¿Cómo comunicar lo que se quiere comunicar? ¿En la comunicación, vale todo? Varios indicios nos muestran que la presencia de un lenguaje violento, ofensivo, considerado

\footnotetext{
prensa para ejemplo y estímulo de los patriotas seglares». «Oficios comunicados», La Prensa Argentina, Buenos Aires, 19 de marzo de 1816.

44. «Convento de la observancia, febrero 28 de 1816», La Prensa Argentina, Buenos Aires, 19 de marzo de 1816.

45. «Nota», La Prensa Argentina, Buenos Aires, 19 de marzo de 1816.
} 
escasamente moral, no pasa desapercibido tanto en la sociedad como en los distintos papeles públicos. En este sentido, conviene detenernos brevemente no solo en la década de 1810, sino también en los primeros años de 1820 para poder entender mejor en qué contexto histórico más amplio escribe el fraile.

En un clásico estudio sobre este período, Halperin realizó un balance del proceso revolucionario de la década de 1810 , destacando el deterioro de la convivencia tanto en la esfera política como la privada. En esta precisa línea, señala que en diferentes territorios del Río de la Plata resultan episodios repetidos los saqueos y las rapiñas después de los combates, los actos de ebriedad, la exhibición de los cuerpos inertes de los enemigos en la vía pública o el castigo público entre vecinos. En rigor, los ha calificado como los «avances de un estilo deliberadamente brutal». Se trata, a su juicio, de un «estilo nuevo» enmarcado en «un deterioro del estilo de convivencia de la élite». En un estudio más reciente, Raúl Fradkin, examinando los partes y los sumarios elaborados durante los años de conflicto bélico, ha puesto el acento en los límites de la estructura estatal con relación a la violencia en las tropas y en las acciones desplegadas por el bandolerismo. ${ }^{46}$

De algún modo, algunos aspectos de este eje problemático pueden advertirse en los primeros años de la década de 1820. Ubiquémonos brevemente. En este último año se produce una crisis inusitada. Entre otras muchas cuestiones: caída del régimen Directorial, gobernadores con una duración efímera en sus mandatos, invasión de la provincia por parte de las fuerzas del litoral y crisis en el erario público y en la producción. La imposición hacia finales de ese año de un gobierno con integrantes del llamado Partido del Orden puso, en cierto modo, nuevamente un centro de autoridad en la provincia. En los primeros años de la década de 1820 se levanta un escenario de contrastes. Por un lado, se ha señalado un clima público de relativa paz, basada centralmente en la enorme ola de reformas sancionadas, entre otras, de carácter electoral, militar y del clero, a lo que hay que sumarle el incentivo a la producción dada a partir de la expansión de la frontera. Sin embargo, al mismo tiempo, se ha advertido que sobre ese mismo escenario se presentan claros indicios de tensión o de conflicto: la oposición federal se encuentra en el exilio y muy lentamente comienza a regresar a la provincia luego de un indulto; se producen distintas conspiraciones y, particularmente, durante la contienda bélica con la República de Entre Ríos, la población de Buenos Aires es movilizada y se hace notar la resistencia de distintos grupos. ${ }^{47}$ Sobre este terreno, mucho más favorable en algunos aspectos pero también salpicado por episodios de tensión y de conflicto, también se reconoce un clima donde prevalece la violencia.

46. Halperin Donghi, Tulio, Revolución y..., cit., pp. 383-384; Fradkin, Raúl, «Los usos de la violencia. La campaña de Buenos Aires durante la década de 1810 vista a través de los sumarios y partes militares», Illes $i$ imperis núm. 15, Barcelona, 2013, pp. 11-27.

47. Ternavasio, Marcela, «Las reformas rivadavianas en Buenos Aires y el Congreso General Constituyente (1820-1827)», en Goldman, Noemí, Revolución, República, Confederación (1806-1852), Nueva Historia Argentina, Buenos Aires, Sudamericana, 1998, pp. 161-197; Herrero, Fabián, «Conflictos políticos, económicos, militares... Buenos Aires y la guerra con la República de Entre Ríos», Pasado Abierto, n. ${ }^{\circ}$ 1, Mar del Plata, enero-junio 2015, pp. 69-90. 
Una mirada a los papeles de Gobierno resulta interesante para poder advertir que existen casos en donde es posible señalar una escena ciertamente dinámica: hay discusiones, hay controles, hay castigos. En las cartas y las solicitudes que pueden registrarse en la administración provincial es posible hallar casos de este tipo. Veamos solo alguno de ellos. En una comunicación, el Gobierno porteño dispone que el Jefe de Policía «aperciba seriamente a D Vicente José Mota Lagosta, por el ofensivo lenguaje que ha usado en la carta que dirigió quejándose contra el Juez de Paz de Morón» pero también por «la falta de verdad en el hecho a que se refiere». En otra nota, dispone que el máximo responsable policial «aperciba a D Valerio Arditi» y le manifieste el «desagrado del Gobierno por el estado procaz en que está concebida su solicitud de renuncia del empleo de médico del Salto», aclarándole que dicho «recurso se reserva proveer».48

Los papeles que circulan en el territorio provincial propiciando la ofensa de otros pobladores también tienen una atención similar. Es lo que puede leerse en el expediente seguido contra el R. P Fr. Martín Arteaga «por la conducta ilícita» que este «observaba en el pueblo de San Nicolás». En esta línea, se hace mención a «varias cartas y versos inmorales escritos por él». La condena no tardó en llegar. Un juez de Primera Instancia del 3r Departamento dispuso que por «su escandalosa conducta» el religioso debía «salir del territorio de la provincia». ${ }^{49}$

El gobierno porteño, a partir de iniciativas de Rivadavia, dispuso una serie de medidas tendientes a regular algunos aspectos de la vida social de la ciudad. Entre ellas, por ejemplo, cómo debían ubicarse los vendedores ambulantes en la Plaza de la Victoria, la sugerencia de que las pulperías sacaran los mostradores a la calle o la prohibición de la entrada al centro del espacio urbano de carretas tiradas por más de dos bueyes o por un vacuno. En este contexto de medidas de control, también pretendió asegurar que los «revendedores y proveedores en las plazas de la ciudad se abstengan de proferir las palabras obscenas con que insultan la decencia pública». ${ }^{50}$

En el dominio de la prensa, el tema provoca discusiones y polémicas. Una muestra de ello es la que se produce en el año 1819 entre nuestro fraile y el periódico El Americano. El fraile es acusado de loco y, sobre todo, de señalar con sus nombres a los responsables de una posible reforma de su Orden. Lo que en las páginas de El Americano se discute es si resulta posible hacer públicos los datos filiatorios de los implicados, ya que el hecho daña su reputación.

48. Véase «Comunicación del Gobierno», 21-9-1822 y 30-9-1822, AGN, Sala X, 32-10-2. Con relación al lenguaje violento y la justicia, véase Fernández, María Alejandra, «Violencia y justicia: las respuestas frente a los insultos en Buenos Aires, 1776-1810», en Peire, Jaime, Mariano Di Pasquale y Arrigo Amadori, Ideologías, prácticas y discursos. La construcción cultural del mundo social, siglos XVII-XIX, Buenos Aires, EUNTREF, 2013, pp. 159-188.

49. Véanse «Expediente seguido contra el R. P Fr. Martín Arteaga», 27-11-1822 y «Orden al Juez de $1{ }^{2}$ Instancia», 27-11-1822, AGN, Sala X, 32-10-2.

50. Citado en Di Meglio, Gabriel, ;Viva el bajo pueblo! La plebe urbana de Buenos Aires y la política entre la revolución de mayo y el rosismo, Buenos Aires, Prometeo, 2007, p. 223 y, a propósito de los cambios implementados por Rivadavia en la ciudad, pp. 222 y 223. 
Otro tema que aparece sobre la prensa es a propósito de la indiferencia que algunas publicaciones periódicas provocaban en los lectores. En otro trabajo, hemos podido mostrar cómo hacia fines de 1814, Manuel Sarratea, funcionario del Directorio en el exterior, alertaba sobre la falta de credibilidad de La Gazeta para dar cuenta de los hechos de Gobierno. Como respuesta, sostenía la necesidad de crear un periódico que se presentase como independiente del poder oficial. Ese reclamo tuvo su traducción concreta en la edición de El Independiente (enero y abril de 1815), redactado por Manuel Moreno y sostenido por el Directorio, quien definía su línea editorial bajo las indicaciones de los secretarios de Carlos Alvear, Nicolás Herrera y Bernardo Monteagudo. Estos casos demuestran que el tema del dominio de la prensa está entre las preocupaciones de por lo menos un sector de la élite y, en este último ejemplo, que se piensan alternativas a la forma de comunicar. ${ }^{51}$

Como se ve, el tema del lenguaje y de cómo comunicar rodea y atraviesa los papeles públicos y son materia de reflexión y también de sanción o de promesa de sanción. Todo este desvío resultó del todo pertinente para poder comprender mejor por qué en la prensa el tema recorre un camino similar. ¿Es lícito emplear cualquier tipo de discurso, se puede escribir de cualquier manera? ¿Se acepta la descalificación, la ofensa, sin discusión? Este tipo de interrogantes impregnan la discusión en torno a una carta publicada por Castañeda.

\section{El debate sobre «la carta tediosa»}

En las columnas de El Censor, en dos números diferentes, se publica una comunicación de un lector firmado con solo tres letras, JVG, quien se muestra ciertamente molesto por un artículo publicado en La Prensa Argentina que cuestiona una carta escrita por el fraile Francisco Castañeda. La parte que particularmente le provoca rechazo e indignación a JVG es cuando justamente se sostiene: «sigue una carta del reverendo Castañeda»; posteriormente, se afirma «digno patriota», e inmediatamente en tono de burla señala «San Pascual nos libre de que su paternidad dé en ser escritor»; y concluye, «iJesús qué carta! Cuidado que puede ser un modelo de estilo epistolar» ${ }^{52}$ Como se ve, se duda tanto de su capacidad como de su talento como escritor. ¿Qué se discute según el lector que asume su defensa? El eje de su argumento puede cifrarse en una pregunta. ¿Cómo se debe escribir en un papel público, y, especialmente, de qué modo debe ejercerse la crítica?

En un comienzo cuestiona al «semanario prensista» porque presenta un estilo de escritura próxima a la descalificación. Esta estrategia editorial tiene un doble perjuicio, ya que «no sólo mortifica a los ofendidos, sino que también pone de mal humor a los lecto-

51. Sobre la polémica entre Castañeda y El Americano, Herrero, Fabián, «¿Reformar...», cit. Sobre el caso de El Independiente, Herrero, Fabián, Monteagudo. Revolución, Independencia, Confederacionismo, Buenos Aires, Ediciones cooperativa, 2005.

52. «Súplica», El Censor, Buenos Aires, 12 de noviembre de 1815. 
res imparciales».53 Al leerse sus páginas salta a la vista que sus responsables no parecen conocer los pormenores del uso de la crítica. En este sentido, sostiene que es necesario «descubrir y corregir con finura los defectos, sin agraviar a los sujetos, evitando sus nombres si es posible», al considerar que es uno de los «más recomendables preceptos de la buena crítica»..$^{54}$

En la opinión del redactor de El Censor, la carta de Castañeda es amistosa y su trayectoria no puede dejar dudas sobre su persona. ${ }^{55}$ Para el lector del órgano de prensa del Cabildo, las columnas de La Prensa Argentina no saben ilustrar como corresponde a la sociedad de Buenos Aires. En este sentido, se pregunta «¿este es el modo de ilustrar a los pueblos? La chocarrería, la ironía insultante, es el primer trabajo que U consagra a la apertura de su periódico». Se trata, en efecto, de una publicación periódica que desborda el plato de la moral que debe tener presente un escritor público. Desde ese lugar incorrecto, se impugna al fraile. Por este motivo, los cuestionamientos remiten a interrogantes que no tienen sentido,

¿qué tachas tiene U que poner a la carta? ¿Qué fue larga? Muéstrenos U la mensura para esta clase de trabajos y nos someteremos a la censura. Dirá U que el estilo es llano y humilde, válgame Dios que intenso esta U en la crítica. ¿No sabe U que aunque el hábito no hace al monje, siempre se ha visto al militar escribir con ardor y valentía, al abogado con brillantez y magisterio, al ministro con mansedumbre y devoción? Y virtuoso recoleto acostumbrado por genio e instituto a la sencillez a desear más bien ser entendido de todos que admira de algunos ¿de qué otro modo habría de escribir?

En la segunda parte de su carta señala que es «conocida» la «moderación» que guían los actos de Castañeda. Todos la conocen: así, el cuestionamiento se revela tan incorrecto como falso. Para terminar con esa noticia falsa sostiene «yo pondría en manos de U obras suyas que lo convencerían de haber partido muy de ligero». Ahora bien, ¿si nuestro sacerdote tiene una imagen reconocida en la ciudad cuál es el motivo que explican los agravios? La respuesta es sencilla, alude a la línea editorial de ese órgano de prensa. Así, concluye,

la única razón por la cual se lo ofende es porque La Prensa Argentina se propuso un método distinto de acción que es la crítica despiadada. Yo no encuentro otro modo de salir de este

53. «Artículo comunicado», El Censor, Buenos Aires, 12 de noviembre de 1815.

54. «Convengamos $\mathrm{Sr}$ editor en que debemos respetarnos mutuamente los hombres, hablando y escribiendo, las sátiras mordaces y los chistes picantes lejos de corregir exasperan, todo lo que no consiga la razón santa, y la dulzura encantadora, no hay que esperarlo de la aspereza y acrimonia.» «Súplica»..., cit.

55. «Jamás creyó el P. Castañeda, ni a persona alguna pudo ocurrir que una carta amistosa que no ha sido más que un desahogo de su genio sencillo, concluida en las emociones del gozo al ver en planta un establecimiento debido en parte a sus desvelos y al deseo de satisfacer prontamente al autor de las observaciones, diese margen al editor de la Prensa Argentina para pifiar de un modo tan poco urbano a un sujeto de carácter que el mismo confiesa ser recomendable, no solamente (como el dice) por un zelo en fomentar la ilustración, sino por muchos más títulos digno de nuestro aprecio y respeto.» «Súplica...», cit. 
berenjenal en que $\mathrm{U}$ se ha metido, sino contemplándolo comprometido por su prospecto con el público a dar palos y por eso creyó que era un deber suyo señalar su primer número con repartirlos a diestro y siniestro. ${ }^{56}$

El tema de la crítica remite también al de los lectores. ¿A quién se dirigen los periódicos? ¿Se trata de un público ilustrado? En este sentido, considera que los porteños han adelantado mucho en su ilustración durante el proceso revolucionario y en ese aprendizaje ya se ha superado a España. En este punto se pregunta cuál es el estilo que se prefiere: ¿«el moderado o el dar palos»?

Es preciso que U confiese que este público está más ilustrado que lo que U cree (aunque sea porteño) en los cinco años que lleva de revolución se ha familiarizado con el buen gusto que muchas veces ha brillado en nuestros periódicos, tiene su paladar muy delicado, y lo espero le da dentera, esa repetición y amenazas de palos, aun en chanza choca, en un país donde cada hombre no tiene en su casa alhaja de más aprecio que el fusil, sable y pistolas y donde hasta los niños no tienen más juguete que las armas, pega muy mal eso de garrotes; la moderación es el carácter de este pueblo aguerrido, y todo papel que no este concebido en este delicioso estilo, tendrá tan mala acogida como la crítica de la carta del padre Castañeda [destacado por el autor]. ${ }^{57}$

La respuesta, en verdad, no tarda en llegar. Aparece en un artículo publicado en La Prensa Argentina bajo el sugestivo título «Garrotazo a los censores números 8 y 9». ¿Qué dice? Se hace una distinción entre las cartas que se escriben en un espacio privado y aquellas que deben ser publicadas. Castañeda es criticado porque si usa este último ámbito no puede hacerlo de un modo que al lector no le atraiga ni le interese. Siguiendo esta línea de razonamiento, no hay duda de que las que publica el fraile son «cartas tediosas».58 Para respaldar su afirmación, sostiene: «apelo al conocimiento y laudable ingenuidad del mismo religioso que lo diga», pero a su vez también al «editor antiguo de La Gaceta», a quien considera «con juicio suficiente para discurrirlo», para que señale «si semejantes cartas son propias de ese diario ni merecen publicarse en un pueblo literato».

De esta manera, propone que quede claro que su impugnación es por lo que se expresa en un papel puntual y no en una descalificación al sujeto que la escribió. «En mis expresiones», señala en este sentido, «nada hay de personal, ni ofensivo al honor del respetable padre Castañeda». Lo que sí pretende advertir es una «critica pronta y festiva propia del plan de mi periódico y análoga a este género de papeles que piden una crítica aguda y fugaz». Considera, igualmente, que su artículo puede ser percibido como «una zumba inocente» y que la misma no puede «ser movida por un espíritu de malignidad, ni menos de dañar la buena opinión del padre», a quien afirma «estimo y encomio en mi

56. «Finaliza el artículo principiado en el número anterior», El Censor, Buenos Aires, 19 de noviembre de 1815.

57. Ibidem.

58. «Garrotazo a los censores números 8 y 9», La Prensa Argentina, Buenos Aires, 24 de noviembre de 1815. 
misma critica, proponiéndole como...digno de imitarse por las ventajas que deduciría la patria». ${ }^{59}$

¿Cómo concluye esta polémica? Para cerrar el sentido negativo de este cambio hostil de opiniones el protagonista de la controversia es convocado finalmente por el redactor de La Prensa Argentina. ¿Qué hace el franciscano? Escribe una nota en la que primero elogia la actitud abierta y bondadosa del responsable del periódico por invitarlo a terminar de un golpe seco con «la descomunal contienda entre U. y D. JGV». En este sentido, sostiene que admite «gustoso el oficio de árbitro componedor», confiando en que su «fallo no podrá desagradar a los contendores». ${ }^{60}$

A sus ojos, «la carta en cuestión es amistosa, familiar y catequista». Por consiguiente todo «su mérito consiste no en la palabra, sino en las verdades que expresa». ¿Cuál es esa verdad? Esa verdad es el fomento de la ilustración y la necesidad de que los periodistas la fomenten de todas las formas posibles. Admite, al mismo tiempo, que no fue la forma adecuada para difundir sus creencias. «Le confieso a U. con ingenuidad», dice Castañeda, que

al escribir mi tediosa carta se me caía de las manos, y que en aquellos momentos de aflicción todo era clamar a los periodistas para que como más instruidos, y menos lerdos que yo empleasen sus elocuentes plumas en animar a los patriotas y estimuladas al único necesario que es la educación de los pueblos. ${ }^{61}$

El fraile, como se ve, escribe, con cierta ironía, situándose como un religioso y dejando en claro que no es un periodista: es justamente a ellos a quienes corresponde escribir de un modo que llegue al pueblo para educarlo. El tema en cuestión es que, con relación a la instrucción, la prensa es vital como vehículo mediador con el pueblo y, a los ojos del fraile, no lo está haciendo como corresponde. Esta es la importancia de la intervención de Castañeda. Que la cuestión de encontrar la mejor manera de promover la educación es urgente lo prueba su diagnóstico, que es claramente sombrío: «el diluvio y abismos de ignorancia tiene ya abiertas sus fauces para tragarse a la generación venidera», y como van las cosas, «tiempo vendrá en que no se encuentre quien escriba cartas». Su situación, entonces, no es la mejor para ese fin. En este sentido, admite las críticas recibidas y confiesa «vedme por una parte animado del zelo que $U$ reconoce en mí», y por otra «sin facultades, ni talentos». Estas resultan las «dos causas que dieron motivo a expresarme en los términos que U lamenta».62

En esta línea, insiste en que la respuesta para acabar con la ignorancia que compromete el futuro de la revolución, la de sus protagonistas futuros, es la ilustración, que debe aplicarse de cualquier manera.

\footnotetext{
59. Ibidem.

60. «Variedades», La Prensa Argentina, Buenos Aires, 31 de octubre de 1815.

61. Ibidem.

62. Ibidem.
} 
Suplico a U. que dispensado mi importunidad, y defectos geniales se digne consolarme empleando sus talentos en promover la ilustración: válgase también para esto de la ironía, de la sátira, del sarcasmo y de todo estilo malo y bueno que yo me ofrezco a ser su payaso, ya que no merezco, ni se, ni puedo ser su director. ${ }^{63}$

En síntesis, lo que a Castañeda (y también al redactor de La Prensa Argentina) le interesa hacer ver y discutir es la forma que debe adquirir la difusión de las ideas. Defiende que no puede hacerse de cualquier modo, ni debe dejarse librada al simple azar. A sus ojos, el problema central de la revolución es la falta de educación.

Esta perspectiva se conecta directamente con una idea que puede percibirse desde las décadas finales del siglo XVIII, en donde los cambios, la propaganda, y la literatura están atados. En este sentido, se ha llamado la atención sobre cómo el tiempo de la acción y de las posibilidades de mutaciones es también el de la propaganda. Y la propaganda debe justamente recurrir a la literatura para el logro de aquellos movimientos. «La idea más común entonces es que la literatura y las bellas artes ayudan», entre otras, a la «filosofía, o la ley que es su expresión social, haciendo que la acepte el público gracias a los atractivos que les son propios». ${ }^{64}$ Este debate sobre las formas de comunicar abre un espacio para cambiar ideas al respecto y, al mismo tiempo, sirve para instalar un tema elemental para todos aquellos que pretenden ganar el oído de los porteños.

En suma, el problema de cómo comunicar las creencias con las que pretende incidir en el espacio público resulta vital para Castañeda porque lo que quiere es, de algún modo, cambiar la «cabeza» de los hombres de la élite o la de sus futuros reemplazantes, en cuanto está convencido que la política revolucionaria entró en un camino por lo menos equivocado. Que esto es así lo prueban sus otras actividades paralelas, su ya comentado impulso a las prácticas asociativas que tienen como fin que los jóvenes, la élite futura, se eduquen con los valores de la iglesia.

\section{A modo de conclusión}

En una primera parte hemos intentado advertir las iniciativas asociativas impulsadas por el fraile Castañeda, las cuales son mencionadas por algunos de sus biógrafos pero no habían sido examinadas. Aprovechando una investigación de González Bernaldo, hemos podido mostrar que la incursión en la empresa asociativa del franciscano no es obra exclusiva de él, sino que su iniciativa se inserta en un espacio, Buenos Aires, en donde la huella de esa práctica tiene una historia larga. Su participación se inscribe en un momento previo al auge de este tipo de asociaciones. Se trataría, por otro lado, de un ámbito en que los hombres solo se relacionan con las ideas: su objetivo es una didáctica que preten-

63. Ibidem.

64. Benichou, Paul, La coronación del escritor 1750-1830. Ensayo sobre el advenimiento de un poder espiritual laico en la Francia moderna, México, Fondo de Cultura Económica, 1986, p. 66. 
de cambiar los llamados «abusos» y «vicios» y en la promoción de ideas ligadas al trabajo. No hay allí un principio igualitario que incluya a los sectores menos favorecidos, sino que pertenecen al círculo de la élite local. Finalmente, hemos visto que la iniciativa pretende apoyarse en la esfera estatal. Sin embargo, en esta empresa, como en otras ligadas a la difusión de la ilustración, el fraile tiene una excesiva confianza. En este sentido, hemos podido advertir, por una parte, que su obra es ponderada por la prensa y algunas instituciones mientras que, por otra parte, los resultados finales son escasos o nulos, ya que sus iniciativas no pueden mantenerse en el tiempo y en su desarrollo lo hacen con problemas.

En una segunda parte, hemos analizado aquí una polémica, no advertida por los biógrafos de Castañeda, sobre el modo en que se debe informar y comunicar al público. Lo que pone en discusión el fraile con su intervención es que, luego de cinco años de revolución, se presenta un problema de comunicación. En su opinión, es necesario utilizar todos los medios posibles, como la ironía o la sátira, entre otras, para poder tener cierta resonancia en el espacio público, con la intención de incidir en materia educativa de acuerdo a los contenidos básicos de la iglesia. Es lo que justamente hace a partir de la década de 1820, cuando sus múltiples periódicos tienen justamente estos propósitos.

\section{Fuentes}

Archivo General de la Nación, Fondo Gobierno, Sala X, 32-10-2.

\section{Publicaciones periódicas y documentos éditos}

Archivo General de la Nación, Acuerdos del Extinguido Cabildo de Buenos Aires, serie IV, t. V, Buenos Aires, 1927.

Amonestaciones al Americano, Primera Amonestación al Americano. (1819)

El Censor (1815)

El Despertador Teofilantrópico (1821)

El Desengañador gauchi político (1820-1821)

Eu Nao Me Meto con Ninguem (1821)

La Gazeta. (1815-1816)

La Prensa Argentina (1815-1816)

Los Amigos de la Patria y de la Juventud (1816)

\section{Bibliografía}

Auza, Néstor, «Estudio preliminar», en Doña María Retazos. Francisco de Paula Castañeda, Buenos Aires, Taurus, 2001.

Baltar, Rosalía, «Francisco de Paula Castañeda: amanuense y autor», Cuadernos de Ilustración y Romanticismo, núm. 20, Universidad de Cádiz, 2014, pp. 20-41.

Benichou, Paul, La coronación del escritor 1750-1830. Ensayo sobre el advenimiento de un poder espiritual laico en la Francia moderna, México, Fondo de Cultura Económica, 1986. 
Caballero Campos, Herib y Carlos Gómez Florentín, «En un estilo claro, sencillo y sobre todo, tan útil». El Semanario De Avisos y Conocimientos Útiles (1853-1868)», en Pasino, Alejandra y Fabián Herrero (comp.), Prensa y Política en Iberoamérica, Buenos Aires, Editorial de la FFyL, UBA, 2018 (en prensa).

Capdevilla, Arturo, La Santa Furia del padre Castañeda. Cronicón porteño de frailes y comefrailes donde no queda títere con cabeza, Madrid-Barcelona, Espasa-Calpe, 1933.

Castañeda, Francisco, «Arenga de la Academia de dibujo», en Segura, Juan, El padre Castañeda y su programa cultural en Paraná, Paraná, Editorial Nueva Impresora, 1948.

Di Meglio, Gabriel, ; Viva el bajo pueblo! La plebe urbana de Buenos Aires y la política entre la revolución de mayo y el rosismo, Buenos Aires, Prometeo, 2007.

Fernández, María Alejandra, «Violencia y justicia: las respuestas frente a los insultos en Buenos Aires, 1776-1810», en Peire, Jaime, Mariano Di Pasquale y Arrigo Amadori, Ideologías, prácticas y discursos. La construcción cultural del mundo social, siglos XVII-XIX, Buenos Aires, EUNTREF, 2013, pp. 159-188.

Furlong, Guillermo, Vida y obra de Fray de Paula Castañeda: un testigo de la naciente patria argentina: 1810-1830, Buenos Aires, editorial Castañeda, 1994.

Fradkin, Raúl, «Los usos de la violencia. La campaña de Buenos Aires durante la década de 1810 vista a través de los sumarios y partes militares», Illes $i$ imperis, núm. 15, Barcelona, 2013, pp. 11-27.

Fracchia, Diego, «Poder político y reformas educativas en la Buenos Aires revolucionaria: debates y representaciones en la prensa, 1810-1820», en Peire, Jaime, Mariano Di Pasquale y Arrigo Amadori, Ideologías, prácticas y discursos. La construcción cultural del mundo social, siglos XVIIXIX, Buenos Aires, EUNTREF, 2013, pp. 293-322.

González Bernaldo, Pilar, Civilidad y política en los orígenes de la nación Argentina. Las sociabilidades en Buenos Aires, 1820-1852, Buenos Aires, Fondo de Cultura Económica, 2008.

Halperin Donghi, Tulio, Revolución y guerra. Formación de una élite dirigente en la Argentina criolla, México, Siglo XXI, 1972.

Herrero, Fabián, Monteagudo. Revolución, Independencia, Confederacionismo, Buenos Aires, Ediciones cooperativa, 2005.

—, «La idea de independencia durante los días de la Revolución americana y de la Restauración europea. El difícil sermón patriótico de Francisco Castañeda en la Catedral de Buenos Aires», Iberoamericana. América Latina, España, Portugal, vol. XII, núm. 45, Instituto Ibero-Americano, Berlín, 2012, pp. 59-79.

—, «Reformar las instituciones de la iglesia? La polémica entre Francisco Castañeda y Feliciano Cavia. Buenos Aires, hacia fines de 1810», Revista Eletrônica do Programa de Pós-Graduação em Ciências Sociais da UFJF <http://www.editoraufjf.com.br/revista/index.php/csonline/index>, núm. 13, 2012, pp. 48-78.

—, «De la política colonial a la política revolucionaria», en Fradkin, Raúl, Historia de la provincia de Buenos Aires. De la Conquista a la crisis de 1820, Buenos Aires, Unipe-edhasa, 2012, pp. 325-353.

—, «Conflictos políticos, económicos, militares...Buenos Aires y la guerra con la República de Entre Ríos», Pasado Abierto, núm. 1, Mar del Plata, enero-junio 2015, pp. 69-90.

—, «La guerra revolucionaria. Algunas propuestas en el dominio público de Buenos Aires», inédito, 2018.

Ibarguren, Carlos, Las sociedades literarias y la Revolución Argentina (1800-1825), Buenos Aires, Espasa Calpe, 1937. 
Lafit, Facundo, «Usos de escritos y conceptos políticos en ambas márgenes del Plata y del Atlántico. La Gazeta de Montevideo, entre Cádiz y Buenos Aires», en Pasino, Alejandra y Fabián Herrero (comp.), Prensa y Política en Iberoamérica, Buenos Aires, Editorial de la FFyL, UBA, 2018 (en prensa).

Molina, Eugenia, El poder de la opinión pública. Trayectos y avatares de una cultura política en el Río de la Plata, 1800-1852, Santa Fe, ediciones UNL, 2008.

Nanni, Facundo, «El arte de la difamación: las disputas al interior de la élite en el Tucumán de la década de 1820», Revista Navegamérica, núm. 11, Murcia, Universidad de Murcia, 2013, pp. 15-37.

—, «Precario como el papel. Los primeros periódicos en el Tucumán decimonónico», en Pasino, Alejandra y Fabián Herrero (compiladores), Prensa y Política en Iberoamérica, Editorial de la FFyL, UBA, 2018 (en prensa).

Otero, José Pacífico, El padre Castañeda: su obra ante la posteridad y en la bistoria, Buenos Aires, Cabaut y Cía, 1907.

Roman, Claudia, La prensa de Francisco de Paula Castañeda: sueños de un reverendo lector (18201829), Biblioteca Orbis Tertius/10, Universidad Nacional de La Plata, 2014.

Saldias, Adolfo, Vida y escritos del Padre Castañeda, Buenos Aires, A. Moen y hermano, 1907.

Segura, Juan, El padre Castañeda y su programa cultural en Paraná, Paraná, Editorial Nueva Impresora, 1948.

Ternavasio, Marcela, «Las reformas rivadavianas en Buenos Aires y el Congreso General Constituyente (1820-1827)», en Goldman, Noemí, Revolución, Republica, Confederación (1806-1852), Nueva Historia Argentina, Buenos Aires, Sudamericana, 1998, pp. 161-197.

Torre Revello, José. «Fiestas y costumbres», en Academia Nacional de la Historia, Historia de la Nación Argentina. De los orígenes hasta la organización definitiva en 1862, Buenos Aires, Academia Nacional de la Historia, 1951, pp. 40-62.

Troisi Melean, Jorge, Socios incómodos. Los franciscanos de Córdoba en una era de transformaciones (1767-1829), Rosario, Prohistoria, 2016. 